\title{
Evaluation of Knowledge and Awareness of Dentists and Dental Students About Human Papillomavirus Vaccination and Oropharyngeal Cancer Relationship
}

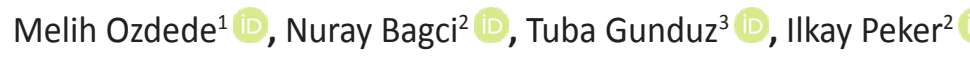 \\ ${ }^{1}$ Pamukkale University, Faculty of Dentistry, Department of Dentomaxillofacial Radiology, Denizli, Turkey. \\ ${ }^{2}$ Gazi University, Faculty of Dentistry, Department of Dentomaxillofacial Radiology, Ankara, Turkey. \\ ${ }^{3}$ Gazi University, Faculty of Education, Division of Assessment and Evaluation in Education, Ankara, Turkey.
}

Correspondence Author: Melih Ozdede

E-mail: melihozdede@gmail.com

Received: $14.06 .2020 \quad$ Accepted: 27.08 .2020

\begin{abstract}
Objective: As the incidence of oropharyngeal cancer associated with human papillomavirus has increased rapidly in recent years, the role of dentists on this issue is also increasing. This study aims to determine the knowledge and awareness of dentists and dental students about human papillomavirus vaccination and the relationship of oropharyngeal cancer.

Methods: A total of 209 participants, consisting of 82 dentists and 127 dental students filled out the questionnaires about the general human papillomavirus knowledge, human papillomavirus - oropharyngeal cancer relationship, and human papillomavirus vaccination. The Fisher Exact and the Mann Whitney $U$ tests were used for determining the difference between the two groups.

Results: The majority of the respondents answered the general questions about human papillomavirus correctly. Almost all of the participants in our study were found to have high awareness about the human papillomavirus - oropharyngeal cancer relationship, most of them did not have enough information about the human papillomavirus - related oropharyngeal cancers have a better prognosis than other oropharyngeal cancers. Both dentists and dental students stated that they did not think they had enough information about human papillomavirus vaccination. Dental students were more conscious and more motivated than dentists in recommending human papillomavirus vaccination to their patients $(p<0.05)$.

Conclusion: Our study showed that dentists and dentistry students had a high level of knowledge in general subjects related to human papillomavirus. It was determined that the knowledge of both groups was insufficient regarding the human papillomavirus - oropharyngeal cancer relationship and human papillomavirus vaccination, and the participants were eager to overcome these shortcomings.
\end{abstract}

Keywords: Dental education, dental student, human papillomavirus, human papillomavirus vaccines, oropharyngeal cancer

\section{INTRODUCTION}

Human papillomavirus (HPV) is a small, enveloped, doublestranded, and circular DNA virus (1). HPV, the most common sexually transmitted infection in the world, is known for causing cervical cancer, and its relationship with oropharyngeal cancer (OPC) has been emphasized in recent years (2). The virus can be transmitted to the oral cavity through sexual contact or auto-infection, rarely at birth perinatally $(1,3,4)$. HPV contamination to the oral region is more related to the number of previous oral sex and oral kissing partners than to the number of vaginal sex partners $(1,4,5)$. The prevalence of this virus, which can cause both HPV infections and HPV-related head and neck cancers, in the oral mucosa, ranged from 0.6 to $81 \%(1,4,5)$.

Head and neck squamous cell carcinomas are the sixth most common cancers in the world (1). Although there have been

serious advances in the diagnosis and treatment process in recent years, the mortality rate is still high and causes an average of 200 thousand deaths per year (6). The five-year survival rate is about $50 \%$, and in the case of metastasis, the rate drops to $26 \%$ (6). Tobacco and alcohol use are among the most common risk factors for OPCs (1). Besides, some HPV types have recently been shown to be an important risk factor for OPC (3). While the type 6 and type 11 of HPV in the low-risk group cause benign papillomatous lesions in the oral mucosa, the type 16 and type 18 groups of the virus are at high risk and may cause OPCs (1).

HPV prevalence in patients with whole OPCs has been reported to range from $0 \%$ to $91 \%$ (1). It is stated that proportional changes vary according to geographical features, sample type, preparation method, and virus detection method (7). 
Ninety percent of OPC cases have been shown to have highrisk HPV type-16 (6). HPV-related OPC is more common in young male patients with high socioeconomic status and has a better prognosis than head and neck cancers not associated with HPV $(3,8)$. HPV-related OPC usually occurs in the tongue base and posterior oropharynx (2).

The incidence of HPV-related OPC is increasing day by day. HPV Type 16 and Type 18, which are the cause of $90 \%$ of HPV-related OPCs, can be prevented by HPV vaccination. HPV vaccination not only reduces the incidence of cervical and anal cancer but also reduces the incidence of HPV-related OPC (9). Knowing the importance of HPV vaccination and directing patients to vaccination is important for the prevention of HPV-related OPCs (10). Although the HPV vaccine is included in the vaccination schedule in developed countries, it is not included in the routine vaccination schedule in many countries, including Turkey (11). In a previous study (12), it has been reported that the biggest obstacle in the spread of HPV vaccination is that healthcare professionals do not have enough awareness and knowledge in this regard.

Although there are studies investigating the knowledge of dentists about HPV abroad, to the best of our knowledge, there is no study investigating the knowledge levels and awareness of dentists or dental students about the relationship between HPV vaccination and HPV-related OPCs in our country. The aim of this study is to determine the knowledge level and awareness of dentists and dental students about HPV vaccination and OPC relationship.

\section{METHODS}

Before the study, ethical approval was obtained from the Ethics Committee of Gazi University (No: 91610558604.01.01, Date of approval: 07.04.2020). The questionnaires were prepared on an online survey website (www.surveey. com) and the link was sent to the participants via e-mail and a mobile phone application (WhatsApp Inc, Menlo Park, CA, USA). The students participating in this study were selected from two dental schools. The participants were informed that their identity information (name, or ID number) would not be requested. It was stated at the beginning of the questionnaire that the study was based on volunteerism, and those who agreed to participate in the study started to answer the questionnaire.

\subsection{Measuring Tools}

A measurement tool (Appendix) consisting of five categories: (A) demographic features (four items), (B) general HPV knowledge (16 items), (C) HPV-OPC relationship (six items), (D) HPV vaccination information (11 items), and (E) HPV vaccination survey (13 items) was applied. B, C and D categories were prepared as "True-False" test type and E was 5-point Likert type scale between "I disagree at all" and "I totally agree". In preparing the true/false questions, Rutkoski et al.'s (13) and Patel et al.'s (10) studies were used, and in the preparation of the survey items, Arnell et al.'s (9) and Patel et al.'s (10) studies were used. In translating the items from English to Turkish, specialist dentists, and experts' opinions (expert of measurement and evaluation) were received. According to their feedback, the final version of the survey was obtained.

\subsection{Data Analysis}

The measurement tools used in the research were collected online; all of the items were responded by the participants. Therefore, there was no missing data in the data set. Since the questionnaires did not go through a test or scale development process, total scores were not obtained, and all analyzes were conducted on an item basis. The Fisher Exact test was used to test the difference between the dentists and the dental students in answering the True/False information questions correctly. The Mann Whitney $U$ test was used to determine whether these two groups differed in answering other questionnaire items. The level of statistical significance was set at 0.05 for all analyzes performed in this study. Statistical analyzes were performed using R (R Core Team, Vienna, Austria).

\section{RESULTS}

A total of 209 participants, consisting of 82 dentists and 127 dental students responded to the survey. The mean age of the dentists was $31.8 \pm 8.4$ (ranged from 23 to 53 ) while the age of dental students was between 18 and 24, with a mean of $21.8 \pm 1.3$. The frequency of the demographic characteristics of the participants in the study is presented in Table 1.

Table 1. Demographic Features of Dentists and Dental Students.

\begin{tabular}{|c|c|c|c|c|}
\hline Participants & & Variables & $\begin{array}{c}\text { Number } \\
\text { (n) }\end{array}$ & $\begin{array}{l}\text { Percent } \\
\text { (\%) }\end{array}$ \\
\hline \multirow{15}{*}{$\begin{array}{l}\text { Dentists } \\
(n=82,100 \%)\end{array}$} & \multirow{2}{*}{ Gender } & Female & 65 & 79.3 \\
\hline & & Male & 17 & 20.7 \\
\hline & \multirow{10}{*}{ Specialty } & Oral surgery & 4 & 4.9 \\
\hline & & Oral radiology & 13 & 15.9 \\
\hline & & Endodontics & 3 & 3.7 \\
\hline & & Oral Pathology & 1 & 1.2 \\
\hline & & Orthodontics & 14 & 17.1 \\
\hline & & Pediatric dentistry & 15 & 18.3 \\
\hline & & Periodontology & 12 & 14.6 \\
\hline & & Prosthodontics & 4 & 4.9 \\
\hline & & Restorative dentistry & 2 & 2.4 \\
\hline & & General dentist & 14 & 17.1 \\
\hline & \multirow{3}{*}{$\begin{array}{l}\text { Experience } \\
\text { (years) }\end{array}$} & 1-4 years & 39 & 47.6 \\
\hline & & $5-9$ years & 37 & 45.1 \\
\hline & & 10 years and over & 6 & 7.3 \\
\hline \multirow{5}{*}{$\begin{array}{l}\text { Dental } \\
\text { students } \\
(n=127,100 \%)\end{array}$} & \multirow{2}{*}{ Gender } & Female & 92 & 72.4 \\
\hline & & Male & 35 & 27.6 \\
\hline & \multirow{3}{*}{$\begin{array}{l}\text { Education } \\
\text { level }\end{array}$} & Third years of school & 44 & 34.6 \\
\hline & & $\begin{array}{l}\text { Fourth years of } \\
\text { school }\end{array}$ & 52 & 40.9 \\
\hline & & Fifth years of school & 31 & 24.4 \\
\hline
\end{tabular}


Regarding Category B, the number of dentists who responded the items correctly was higher than the number of dental students for almost all items. There were statistically significant differences $(p<0.05)$ between two groups for the items $6,7,9,13,15$, and 16 . Responses to the items 11,14 and 18 were statistically similar (Table 2, Figure 1 ). On the subject of Category $C$, there was no statistical difference

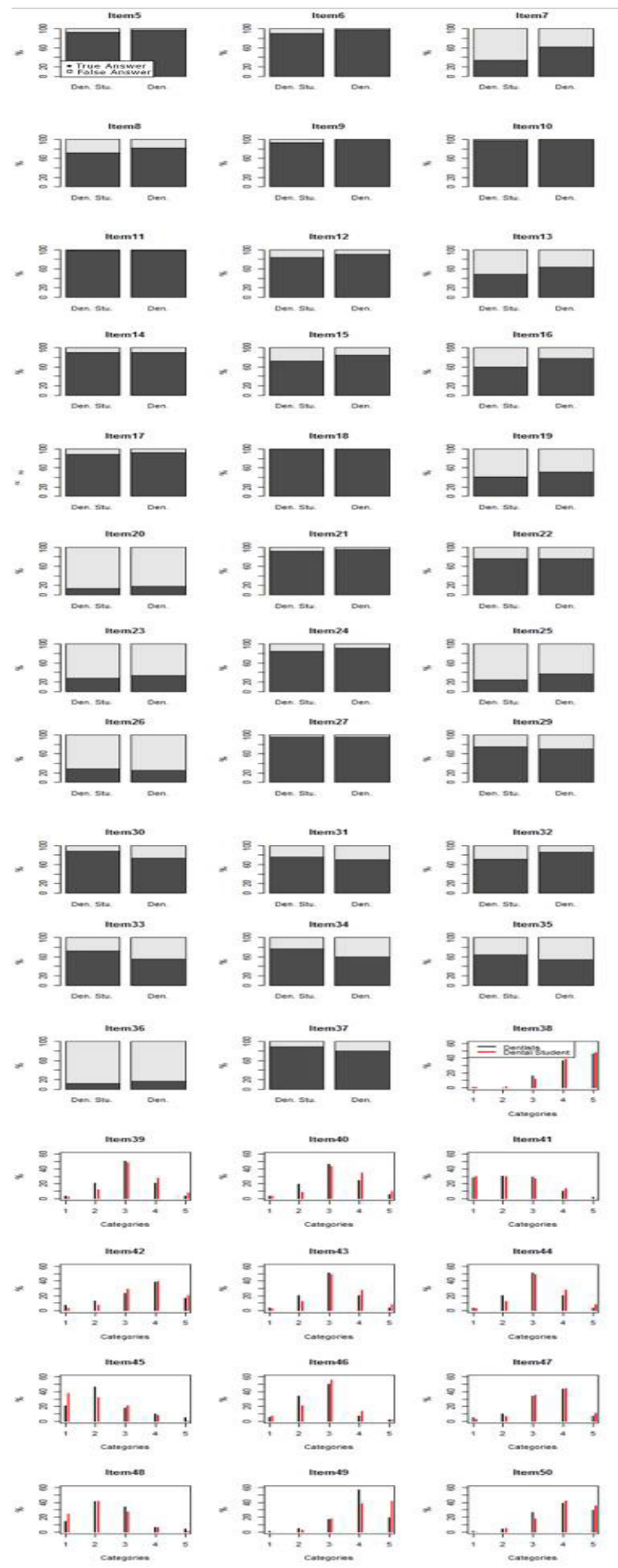

between the groups in the results of these items (Table 2, Figure 1). Regarding Category $D$, dentists responded more accurately than dental students $(p<0.05)$ for the items 28 and 32 , while dental students gave a statistically significantly higher correct response compared to dentists $(p<0.05)$ in the items of 30, 33, and 34 (Table 2, Figure 1).

Table 2. Fisher Exact Test Results on General HPV Knowledge Items, HPV-OPC Knowledge Items, and HPV Vaccination Knowledge Items.

\begin{tabular}{|c|c|c|c|}
\hline \multirow{2}{*}{ Items } & \multicolumn{2}{|c|}{$\begin{array}{c}\text { Number and rates of the correct } \\
\text { answerers }(n, \%)\end{array}$} & \multirow{2}{*}{$p$ value } \\
\hline & $\begin{array}{l}\text { Dentists } \\
(n=82)\end{array}$ & $\begin{array}{l}\text { Dental students } \\
\quad(n=127)\end{array}$ & \\
\hline 5 & $80(97.6 \%)$ & $117(92.1 \%)$ & 0.132 \\
\hline 6 & 81 (98.8\%) & $115(90.6 \%)$ & $0.018^{*}$ \\
\hline 7 & $51(62.2 \%)$ & $43(33.9 \%)$ & $0.000 *$ \\
\hline 8 & $67(81.7 \%)$ & 91 (71.7\%) & 0.103 \\
\hline 9 & $82(100.0 \%)$ & $119(93.7 \%)$ & $0.024 *$ \\
\hline 10 & $82(100.0 \%)$ & 125 (98.4\%) & 0.521 \\
\hline 11 & 81 (98.8\%) & $125(98.4 \%)$ & 1 \\
\hline 12 & 74 (90.2\%) & $106(83.5 \%)$ & 0.219 \\
\hline 13 & $52(63.4 \%)$ & $62(48.8 \%)$ & $0.047^{*}$ \\
\hline 14 & 74 (90.2\%) & $115(90.6 \%)$ & 1 \\
\hline 15 & $69(84.1 \%)$ & $91(71.7 \%)$ & $0.045^{*}$ \\
\hline 16 & 64 (78.0\%) & 76 (59.8\%) & $0.007^{*}$ \\
\hline 17 & $76(92.7 \%)$ & $113(89.0 \%)$ & 0.473 \\
\hline 18 & $82(100.0 \%)$ & $127(100.0 \%)$ & 1 \\
\hline 19 & $42(51.2 \%)$ & $53(41.7 \%)$ & 0.202 \\
\hline 20 & $15(18.3 \%)$ & 17 (13.4\%) & 0.431 \\
\hline 21 & 78 (95.1\%) & $116(91.3 \%)$ & 0.413 \\
\hline 22 & $62(75.6 \%)$ & $96(75.6 \%)$ & 1 \\
\hline 23 & $28(34.1 \%)$ & $36(28.3 \%)$ & 0.443 \\
\hline 24 & 75 (91.5\%) & $108(85.0 \%)$ & 0.202 \\
\hline 25 & $30(36.6 \%)$ & $31(24.4 \%)$ & 0.063 \\
\hline 26 & $21(25.6 \%)$ & $36(28.3 \%)$ & 0.751 \\
\hline 27 & $78(95.1 \%)$ & $121(95.3 \%)$ & 1 \\
\hline 28 & 77 (93.9\%) & $103(81.1 \%)$ & $0.013^{*}$ \\
\hline 29 & $58(70.7 \%)$ & $96(75.6 \%)$ & 0.520 \\
\hline 30 & $60(73.2 \%)$ & $112(88.2 \%)$ & 0.009* \\
\hline 31 & $58(70.7 \%)$ & $96(75.6 \%)$ & 0.520 \\
\hline 32 & 71 (86.6\%) & 91 (71.7\%) & $0.012 *$ \\
\hline 33 & 45 (54.9\%) & $91(71.7 \%)$ & $0.017^{*}$ \\
\hline 34 & 49 (59.8\%) & $97(76.4 \%)$ & $0.013^{*}$ \\
\hline 35 & $44(53.7 \%)$ & $82(64.6 \%)$ & 0.148 \\
\hline 36 & 14 (17.1\%) & $16(12.6 \%)$ & 0.421 \\
\hline 37 & 66 (80.5\%) & $113(89.0 \%)$ & 0.107 \\
\hline
\end{tabular}

$* p<0.05$

Regarding Category $\mathrm{E}$, statistically significant differences ( $p<$ 0.05 ) were found between two groups for the items 39, 40, 43, 44, 45, and 49 (Table 3, Figure 1).

Figure 1. Graphical Distribution of the Items 
Table 3. Mann Whitney U Test Results Regarding the Survey For HPV Vaccination.

\begin{tabular}{|c|c|c|c|c|c|c|c|}
\hline \multirow[b]{2}{*}{ Items } & \multicolumn{2}{|c|}{ Dentists } & \multicolumn{2}{|c|}{ Dental students } & \multirow[b]{2}{*}{$\mathbf{U}$} & \multirow[b]{2}{*}{$\mathbf{Z}$} & \multirow[b]{2}{*}{$\begin{array}{c}p \\
\text { value }\end{array}$} \\
\hline & Median & $\begin{array}{c}\text { Mean } \\
\text { rank }\end{array}$ & Median & $\begin{array}{c}\text { Mean } \\
\text { rank }\end{array}$ & & & \\
\hline 38 & 4.00 & 103.67 & 4.00 & 105.86 & 5098.0 & -0.279 & 0.781 \\
\hline 39 & 3.00 & 95.27 & 3.00 & 111.28 & 4409.5 & -2.018 & $0.044^{*}$ \\
\hline 40 & 3.00 & 93.86 & 3.00 & 112.19 & 4293.5 & -2.280 & $0.023^{*}$ \\
\hline 41 & 2.00 & 106.09 & 2.00 & 104.30 & 5118.0 & -0.217 & 0.828 \\
\hline 42 & 4.00 & 99.61 & 4.00 & 108.48 & 4765.0 & -1.084 & 0.278 \\
\hline 43 & 3.00 & 121.35 & 2.00 & 94.44 & 3866.5 & -3.234 & $0.001 *$ \\
\hline 44 & 3.00 & 123.35 & 2.00 & 93.15 & 3702.0 & -3.627 & $0.000^{*}$ \\
\hline 45 & 2.00 & 114.95 & 2.00 & 98.58 & 4391.5 & -2.006 & $0.045^{*}$ \\
\hline 46 & 3.00 & 96.72 & 3.00 & 110.35 & 4528.0 & -1.750 & 0.080 \\
\hline 47 & 4.00 & 100.26 & 4.00 & 108.06 & 4818.0 & -0.977 & 0.329 \\
\hline 48 & 2.00 & 113.79 & 2.00 & 99.33 & 4486.5 & -1.785 & 0.074 \\
\hline 49 & 4.00 & 92.70 & 4.00 & 112.94 & 4198.5 & -2.543 & $0.011^{*}$ \\
\hline 50 & 4.00 & 98.55 & 4.00 & 109.17 & 4678.0 & -1.316 & 0.188 \\
\hline
\end{tabular}

$* p<0.05$

\section{DISCUSSION}

Dentists have an important role in OPC screening, diagnosis, awareness, and patient education. Although the general risk factors of cancers in the oral region are well known, information about the role of viruses in oral cancer risk is unclear (10). The relationship between HPV and OPC has been revealed recently $(3,9,10,13)$. HPV vaccines applied to prevent cervical cancers associated with HPV reduce the incidence of cervical, anal, penile cancers as well as OPCs (14). The most frequently referred physicians are dentists, and during the oral examination, they examine the face, neck, lips, gums, floor of the mouth, tongue, hard and soft palates in detail (14). During the dental examinations, in which patients are evaluated at short intervals, oral cancer screening is also performed. Dentists who have a great responsibility in the prevention of HPV-related oral cancers have sufficient knowledge about HPV vaccination and motivate their patients to vaccinate HPV, making them one of the key healthcare professionals in raising awareness about this issue $(14,15)$. In the literature, limited number of studies have been carried out on this subject in the last few years $(9,10,13)$. However, it has been reported that the knowledge and awareness of dentists on this issue is quite low $(14,16)$. Our study aims to reduce this deficiency in the literature.

As HPV-related OPC rates are increasing, the importance of this issue and its place in dentistry are increasing $(9,17)$. The important role of dentists in the prevention of tobaccorelated OPCs is as important as the HPV-related OPCs, which can be prevented by HPV vaccination (9). HPV-related OPCS have become popular both in the literature and in the media, so patients can request information from dentists and expect them to direct themselves (14). Thus, the knowledge of dentists on this subject should increase and dentists should prepare themselves to talk about this with their patients (14).
Daley et al (14) conducted an HPV survey for dentists, nearly half of the dentists answered the general information sections about HPV correctly. Arnell et al (9) reported that dentists have moderate knowledge about HPV. In the research of Rutkoski et al (13), it was stated that most of the dental students are sufficient in general subjects related to HPV. In our study, the responses of the participants to the general knowledge questions about HPV were substantially correct. On the other hand, the rate of participants indicating that HPV will recover spontaneously was found to be extremely low in the present study. This result is also compatible with the results of Patel et al (10). Regarding the question about HPV's absence of obvious signs, the majority of dentists in Patel et al's study (10) responded correctly, but in our study, the correct response rate was lower for both dentists and students. In the question of increasing the HPV risk of having multiple sexual partners, the correct response rate was found to be high in both Patel et al's study (10) and the participants in our study.

In a study of Applebaum et al (16), only half of the dentists reported that HPV-related OPC information was up to date, which prevented physicians from talking freely to their patients. On the other hand, dental students are quite inadequate in this regard (13). Almost all of the participants in our study were found to have high awareness about the HPV-OPC relationship. Similarly, almost all dentists who participated in Patel et al's study (10) were reported to know that HPV could lead to OPC. However, the correct response rate for HPV-related OPC prognosis, which group of patients is more common and OPC localization in the oral region was found to be quite low in our study. These results are compatible with the study of Patel et al (10). It was stated that the reason for the inadequacy of dentists in these questions may be due to the missing information of dentists in the pathophysiology of HPV and HPV-related OPCs (10).

Regarding the safety or side effects of HPV vaccination, the level of knowledge of dentists participating in our study was found to be high in many questions, consistent with the previous studies $(10,18)$. However, the correct response rate in our study for questions regarding the administration and pricing of HPV vaccines was low for both dentists and dental students. In the study of Rutkoski et al (13), less than half of the dental students were reported to have sufficient knowledge about HPV vaccination.

In the study of Daley et al (14), it was stated that only $9 \%$ of dentists talk with women patients about HPV vaccination and $81 \%$ of them have insufficient information about HPV vaccination. In the study of Arnell et al (9), it was reported that dentists do not think that they have sufficient information about HPV vaccination, therefore they refrained from discussing these issues with their patients. In our study, both dentists and dental students stated that they did not think they had enough information about HPV vaccination, in line with previous reports $(9,10)$. In the present study, most of the participants answered most of the questions about HPV vaccination, but the majority answered the question 
that HPV vaccines were more effective in individuals who have not previously had sexual intercourse. The results of our study also revealed that, if the participants had sufficient knowledge, they were eager to direct their patients to HPV vaccination and to participate in related training. Putting HPV vaccination on the agenda of training, guides, conferences, and publications of professional organizations can increase the awareness of dentists.

Arnell et al (9) determined that almost all of the dentists thought that they should play an active role in the general health of patients, only half of them believed that HPV vaccination was their responsibility. On the other hand, Daley et al (19) reported that dentists think that information about sexual health issues should be done by family physicians or gynecologists. The dentists in Patel et al's study (10) stated that they were neutral for their role in this matter. In our study, the vast majority of the participants think that they should play an active role in the general health of patients, however, the role of dentists in HPV vaccination was found to be moderate. Our results showed that dental students were more conscious and more motivated than dentists in recommending HPV vaccination to their patients, but dental students have less knowledge about when the vaccination is performed. The role of dentists in HPV vaccination and informative announcements of professional organizations on this topic was reported in previous studies (19). The American Dental Association also issued a declaration in late 2018 on promoting the HPV vaccination (20).

In the study of Arnell et al (9), most of the dentists thought that HPV vaccination could encourage young individuals to undergo earlier/risky sexual intercourse, while in our study the participants gave the opposite view. In the same study (9), it was stated that dentists were keen to have their children vaccinated with HPV, similar to our study. In Patel et al's study (10), the item's score on the point that dentists did not have enough time (and should be) to discuss HPV vaccination with their patients was average. While the score of this item was higher in our study, we think that this situation may be related with dentists treat too many patients. in our country.

According to the best of our knowledge, there is no published article on dentists about HPV and HPV vaccination in Turkey. However, it has been determined that there are many studies evaluating the knowledge levels of other healthcare professionals on subjects such as HPV, HPV vaccine, and cervical cancer $(12,21,22)$. In the survey study conducted by Yuksel et al. among hospital staff (12), medical doctors and nurses were reported to have a higher level of correct knowledge about HPV vaccination compared to other healthcare professionals. In the survey conducted by Gorkem et al. with female healthcare workers other than doctors (21), 85.4\% of the participants knew the HPV vaccine. In the same study, it was stated that the highest information rate was $95.7 \%$ for midwives and $86.4 \%$ for nurses (21). It was determined that the participants in our study were aware of the HPV vaccine but there was a lack of information about its application.
In the study of Yuksel et al. (12), 84.9\% of the doctors who participated in the survey stated that they were considering getting their daughter vaccinated with HPV, this rate was reported as $64 \%$ in nurses and $52 \%$ in other healthcare personnel. In the same study, $58.4 \%$ of doctors and $46 \%$ of nurses and other healthcare personnel were reported to consider getting their children vaccinated with HPV (12). In the survey conducted by Gorkem et al. with female healthcare staff other than doctors (21), it was reported that three-quarters of the participants wanted to vaccinate their daughters. In the study conducted by Guducu et al (22), approximately two-thirds of the medical students stated that they will get the HPV vaccination to their daughters (in the future), while only half of the nursing students and healthcare workers were positive about vaccination. Dentists and dental students in our study reported their willingness to get their children vaccinated with HPV.

In the study of Yuksel et al. (12), for the question of "Do you think that the widespread HPV vaccine may increase the frequency of sexual intercourse or polygamy?", it was determined that most of the doctors, nurses, and other health personnel answered no. The participants in our study also largely answered the question negatively. In the study of Ozakar-Akca et al among nurses (23), the rate of those who stated that HPV vaccine has high efficacy in the prevention of cervical cancer is $87.8 \%$, The rate of those who reported that they prevented anal, vulvar and head and neck cancers was reported as $73 \%$. In the same study, the rate of those who think that the HPV vaccine is a preventive feature of genital cancer and warts in both sexes is stated to be $86.9 \%(23)$. The rate of responses given by dentists and dental students to these items in our study was found similar to the study for nurses (23).

One of the limitations of our research is that the participants in our study were from only one country. However, the fact that dentists who filled out the questionnaire had lower professional experience in general, limits the measurement of knowledge of experienced dentists on the subject. In future studies, dentists from all experience levels can be reached with a higher number of participants, and the current status of dentists in different countries can be evaluated. Also, the change of knowledge levels can be examined after the inclusion of HPV topics in training programs.

\section{CONCLUSION}

According to the results of our research, it was determined that dentists and dental students have a high level of knowledge about general issues related to HPV. However, it was found that the knowledge of both groups was insufficient regarding the HPV-OPC relationship and HPV vaccination and the participants were eager to overcome these shortcomings. A larger place should be reserved for HPV-related OPC and $\mathrm{HPV}$ vaccination knowledge, after the graduation to dentists, and dentistry students during the education period. 
Conflict of interest: The authors declare that there is no conflict of interest.

\section{REFERENCES}

[1] Gupta S, Gupta S. Role of human papillomavirus in oral squamous cell carcinoma and oral potentially malignant disorders: A review of the literature. Indian J Dent 2015; 6:9198.

[2] Rutkoski H, Fowler B, Mooney R, Pappas L, Dixon BL, Pinzon LM, Winkler J, Kepka D. Pilot test of survey to assess dental and dental hygiene student human papillomavirus-related oropharyngeal cancer knowledge, perceptions, and clinical practices. J Cancer Educ 2018; 33:907-914.

[3] Güneri P, Gürhan C, Karaca B. The role of the human papilloma virus in head and neck squamous cell carcinoma. EÜ Dişhek Fak Derg 2018; 39:123-124.

[4] D'Souza G, Agrawal Y, Halpern J, Bodison S, Gillison ML. Oral sexual behaviors associated with prevalent oral human papillomavirus infection. J Infect Dis 2009; 199:1263-1269.

[5] Ragin C, Edwards R, Larkins-Pettigrew M, Taioli E, Eckstein S, Thurman N, Bloome J, Markovic N. Oral HPV Infection and sexuality: a cross-sectional study in women. Int J Mol Sci 2011; 12:3928-3940.

[6] Mallen-St Clair J, Alani M, Wang MB, Srivastan ES. Human papillomavirus in oropharyngeal cancer: The changing face of a disease. Biochim Biophys Acta - Rev Cancer 2016; 1866:141150.

[7] Miller CS, Johnstone BM. Human papillomavirus as a risk factor for oral squamous cell carcinoma: A meta-analysis, 1982-1997. Oral Surgery, Oral Med Oral Pathol Oral Radiol Endodontology 2001; 91:622-635.

[8] Gooi Z, Chan JYK, Fakhry C. The epidemiology of the human papillomavirus related to oropharyngeal head and neck cancer. Laryngoscope 2016; 126:894-900.

[9] Arnell TL, York C, Nadeau A, Donnelly ML, Till L, Zargari P, Davis W, Finley C, Delaney T, Carney J. The role of the dental community in oropharyngeal cancer prevention through HPV vaccine advocacy. J Canc Educ 2019. https://doi.org/10.1007/ s13187.019.01628-w.

[10] Patel S, Koskan A, Spolarich A, Perry M, Flood T. Dental professionals' knowledge, attitudes, and practice behaviors related to human papillomavirus vaccination. J Public Health Dent 2020; 80:61-69.

[11] Kartal M, Gunvar T, Limnili G, Hatipoglu S, Guldal D. Birinci basamak hekimleri serviks kanseri ve HPV asisi ile ilgili ne biliyorlar? Turki Aile Hek Derg 2011; 15:1-6 (In Turkish).

[12] Yuksel B, Sencan H, Kucur Kabil S, Gozukara I, Seven A, Polat M, Keskin N. Human papilloma virus (HPV) enfeksiyonu ve HPV aşısı hakkında bilgi düzeyi ve genel eğilimler; Dumlupınar
Üniversitesi - Evliya Çelebi Eğitim ve Araştırma Hastanesi'ndeki doktor, hemşire ve sağıık personellerini içeren anket taraması. Jinekoloji - Obstet ve Neonatoloji Tıp Derg 2015; 12: 64-67 (In Turkish).

[13] Rutkoski H, Tay DL, Dixon BL,Pinzon LM, Mooney R, Winkler JR, Kepka D. A Multi-state evaluation of oral health students' knowledge of human papillomavirus-related oropharyngeal cancer and HPV vaccination. J Cancer Educ 2019. https://doi. org/10.1007/s13187.019.01561-y.

[14] Daley E, Dodd V, DeBate R, Vamos C, Wheldon C, Kline N, Smith S, Chandler R, Dyer K, Helmy H, Driscoll A. Prevention of HPV-related oral cancer: assessing dentists' readiness. Public Health 2014; 128:231-238.

[15] Brewer NT, Fazekas KI. Predictors of HPV vaccine acceptability: A theory-informed, systematic review. Prev Med (Baltim) 2007; 45:107-114.

[16] Applebaum E, Ruhlen TN, Kronenberg FR, Hayes C, Peters ES. Oral cancer knowledge, attitudes and practices. J Am Dent Assoc 2009; 140:461-467.

[17] Chaturvedi AK, Engels EA, Anderson WF, Gillison ML. Incidence trends for human papillomavirus-related and -unrelated oral squamous cell carcinomas in the United States. J Clin Oncol 2008; 26:612-619.

[18] Naleway AL, Henninger ML, Waiwaiole LA, Mosen DM, Leo MC, Pihlstrom DJ. Dental provider practices and perceptions regarding adolescent vaccination. J Public Health Dent 2018; 78:159-164

[19] Daley E, DeBate R, Dodd V, Dyer K, Fuhrmann H, Helmy $H$, Smith SA. Exploring awareness, attitudes, and perceived role among oral health providers regarding HPV-related oral cancers. J Public Health Dent 2011; 71:136-142.

[20] ADA Adopts Policy on HPV Vaccination for the Prevention of Oral HPV Infection [Internet]. [cited 2020 Jun 1]. Available from: https://www.ada.org/en/press room/news-releases/2018archives/october/ada-adopts-policy-on-hpv-vaccination-forthe-prevention-of-oral-hpv-infection.

[21] Görkem Ü, Toğrul C, İnal HA, Salman-Özgü B, Güngör T. Üniversite hastanesinde çalışan yardımcı sağlık personelinin Human Papilloma Virüs ve aşısı hakkında bilgi düzeyleri ve tutumları. Turk Hij Den Biyol Derg 2015; 72:303-310 (In Turkish).

[22] Güdücü N, Gönenç $G$, İşçi $H$, Yiğiter $A B$, Dünder İ. Awareness of human papilloma virus, cervical cancer and HPV vaccine in healthcare workers and students of medical and nursing schools. J Clin Exp Investig 2012; 3:318-325.

[23] Özakar Akça S, Selen F, Büyükgönenç L. Hemşirelerin human papilloma virüs (HPV) enfeksiyonu ve HPV aşısı hakkındaki bilgi düzeyleri: eğitim ve araştırma hastanesi örneği. HEAD 2016; 13:116-121 (In Turkish). 
Appendix. The Items in the Survey and Correct Answers.

\begin{tabular}{|c|c|c|}
\hline $\begin{array}{l}\text { Item } \\
\text { no }\end{array}$ & A. Demographic features & \\
\hline 1 & Gender & \\
\hline 2 & Specialty (for dentists) & \\
\hline 3 & Experience (for dentists) & \\
\hline \multirow[t]{2}{*}{4} & Education level (for dental students) & \\
\hline & B. General HPV knowledge items & Correct answers \\
\hline 5 & HPV is a bacterial infection. & False \\
\hline 6 & Antibiotics can treat HPV. & False \\
\hline 7 & HPV can cause herpes. & False \\
\hline 8 & HPV can cause HIV/AIDS. & False \\
\hline 9 & HPV can cause cervical cancer. & True \\
\hline 10 & HPV can cause genital warts. & True \\
\hline 11 & HPV can be transmitted through sexual contact. & True \\
\hline 12 & An individual with HPV without a genital wart can infect HPV. & True \\
\hline 13 & HPV usually has no obvious signs. & True \\
\hline 14 & A person with HPV can live for many years without realizing this situation. & True \\
\hline 15 & HPV rate is highest in women in their 30 s. & True \\
\hline 16 & Using a condom reduces the risk of HPV contamination. & True \\
\hline 17 & Oral sex can cause transmission of HPV infection. & True \\
\hline 18 & Having more than one sexual partner increases the risk of HPV. & True \\
\hline 19 & Most sexually active people will encounter HPV once in their lives. & True \\
\hline \multirow[t]{2}{*}{20} & HPV usually resolves spontaneously without any treatment. & True \\
\hline & C. HPV-OPC knowledge items & \\
\hline 21 & HPV can lead to OPC. & True \\
\hline 22 & The same HPV types cause genital warts and OPC. & False \\
\hline 23 & OPCs caused by HPV have a worse prognosis than OPCs not associated with HPV. & False \\
\hline 24 & The early stages of OPC associated with HPV are often asymptomatic. & True \\
\hline 25 & HPV-related OPCs are more common in young, well-educated men. & True \\
\hline \multirow[t]{2}{*}{26} & The tongue is the most common site of HPV-related OPCs. & False \\
\hline & D. HPV vaccination knowledge items & \\
\hline 27 & There are vaccines that immunize against some types of HPV. & True \\
\hline 28 & HPV vaccines can protect women against cervical cancer associated with HPV. & True \\
\hline 29 & HPV vaccines can protect men and women against HPV-related anal cancer. & True \\
\hline 30 & HPV vaccines can protect men and women against HPV-related genital warts. & True \\
\hline 31 & HPV vaccines can protect men and women against HPV-related OPC. & True \\
\hline 32 & HPV vaccines have serious side effects. & False \\
\hline 33 & HPV vaccines are expensive. & True \\
\hline 34 & HPV vaccines are covered by health insurance. & False \\
\hline 35 & HPV vaccines are administered in one dose. & False \\
\hline 36 & HPV vaccines are more effective only for people who have never had sex. & True \\
\hline \multirow[t]{2}{*}{37} & HPV vaccine is recommended to be applied to both men and women. & True \\
\hline & E. HPV vaccination survey & \\
\hline 38 & It is important that dentists take an active role in the general medical health of patients. & \\
\hline 39 & The recommendation of HPV vaccination is the responsibility of dentists. & \\
\hline 40 & The recommendation of the HPV vaccine should be within the professional scope and role of a dentist. & \\
\hline 41 & HPV vaccination can encourage young individuals to have an earlier or more risky sexual relationship. & \\
\hline 42 & I have/would have/plan to have HPV vaccination for my children. & \\
\hline 43 & I am knowledgeable about when to apply the HPV vaccine ideally. & \\
\hline 44 & I am knowledgeable about which ages are the most appropriate period for the HPV vaccine in women. & \\
\hline 45 & I am knowledgeable about which ages are the most appropriate period for the HPV vaccine in men. & \\
\hline 46 & If I recommend HPV vaccination to my patients, my patients will get the vaccination. & \\
\hline 47 & There is not enough time to discuss HPV vaccination (and need for it) during appointments. & \\
\hline 48 & I think I have enough information when talking to my patients about HPV vaccination. & \\
\hline 49 & If I have enough information, I will be willing to educate my patients about the importance of the HPV vaccine to prevent OPCs. & \\
\hline 50 & I would be willing to participate in a training program to promote and manage the HPV vaccine in dentistry. & \\
\hline
\end{tabular}

How to cite this article: Ozdede M, Bagci N, Gunduz T, Peker I. Evaluation of Knowledge and Awareness of Dentists and Dental Students About Human Papillomavirus Vaccination and Oropharyngeal Cancer Relationship. Clin Exp Health Sci 2020; 10: 309-315. DOI: $10.33808 /$ marusbed.752850 